\title{
Nitrogen dioxide exposure from domestic gas cooking and airway response in asthmatic women
}

\author{
T P Ng, C S R Seet, W C Tan, S C Foo
}

\begin{abstract}
Background-Previous studies have not found a consistent association between exposure to domestic cooking using gas appliances and exacerbation of asthma. We investigated the immediate airflow response to acute exposure from single episodes of gas cooking, and peak airflow variability from continued exposure to repeated episodes of gas cooking in a group of non-smoking asthmatic women. Methods-Sixteen adult non-smoking women with mild to severe persistent asthma were studied. The acute short term level of nitrogen dioxide $\left(\mathrm{NO}_{2}\right)$ during gas cooking episodes and the mean exposure to $\mathrm{NO}_{2}$ from repeated gas cooking episodes were measured over a 2 week period, as well as proxy measures of frequency of cooking on each day and the length of time spent cooking each day. Their asthma status was monitored using peak expiratory flow rates (PEFR) before and after cooking, 2 week self-recorded serial readings of PEFR, respiratory symptom severity score, and use of rescue bronchodilators for acute asthma attacks. Results-Cooking was significantly associated with an immediate mean fall in PEFR of $3.4 \%(p=0.015$, paired $t$ test $)$. The acute short term $\mathrm{NO}_{2}$ level during cooking was significantly correlated with the fall in PEFR ( $r=-0.579 ; p=0.019)$. The frequency of cooking over a 2 week period was positively correlated with the mean exposure to $\mathrm{NO}_{2}(r=0.529 ; \mathrm{p}=0.042)$. Continued exposure to $\mathrm{NO}_{2}$ over a 2 week period was associated significantly with increased frequency of rescue bronchodilator usage for asthma attacks $(r=0.597 ; p=0.031)$. However, it was negatively associated with PEFR variability $(r=-0.512 ; p=0.051)$ and respiratory symptom severity score $(r=$ $-0.567 ; p=0.043$ ), probably due to the masking effects of bronchodilator treatment.
\end{abstract}

Conclusions-Acute short term exposure to $\mathrm{NO}_{2}$ from single episodes of gas cooking is associated with immediate airflow limitation. Continued exposure from repeated episodes of gas cooking in asthmatic women is associated with greater use of rescue bronchodilators.

(Thorax 2001;56:596-601)

Keywords: nitrogen dioxide; gas cooking; asthma

Returned to authors

5 June 2000

Revised version received

9 April 2001

Accepted for publication

25 April 2001

There are uncertainties in the current literature on the relationship between the effects of gas cooking from the use of domestic gas appliances and respiratory illness. Studies of children have yielded inconsistent results, with some studies showing a lack of association between the presence of a gas cooker or measured nitrogen dioxide $\left(\mathrm{NO}_{2}\right)$ level and respiratory illness, ${ }^{1-4}$ while others have shown an association with increased frequencies of respiratory illnesses..$^{5-8}$ In reviewing the literature, ${ }^{9}$ much of the inconsistency in the results may be explained by methodological problems such as low statistical power, confounding or effect modification by other pollutants, misclassification of exposure, and the use of insensitive measures of health outcome. Gas cooking produces a complex mixture of a wide array of volatile organic compounds, sulphur dioxide, water vapour, particulates, carbon dioxide, and oxides of nitrogen. Nitrogen dioxide is one of a number of nitrogen oxide compounds that are byproducts of combustion and occur in the home environment from the use of gas or other fuels for cooking or heating, as well as from cigarette smoking and traffic fumes. It is an important indoor air pollutant and has been most extensively investigated for its link with bronchial airway responses.

Some population subgroups are at greatly increased risk of respiratory effects from exposures to the combustion byproducts of gas cooking. These include women with greater exposure from frequent use of the gas cooker, and individuals with pre-existing asthma or other allergic respiratory disorders who are more vulnerable. Several studies have shown a positive association between gas cooking and wheeze and lung function in women, ${ }^{10-12}$ and atopic women have been found to have more respiratory symptoms and worse lung function if they cook with gas rather than electricity. ${ }^{13}$

Few studies have examined the effects of the acute short term "peak" exposure during single episodes of gas cooking and continued exposure to repeated episodes of gas cooking on the airway responses in asthmatic patients. It has been suggested that exposure to such "peak" levels may be more detrimental to respiratory health than cumulative exposure levels. ${ }^{89}$ There are also few studies that directly examine the relationship between environmental levels of $\mathrm{NO}_{2}$ measured during gas cooking and airway responses in asthmatic patients. The objectives of the present study were to elucidate the effects of acute short term ("peak") exposure from single episodes of gas cooking and continued short term exposure to repeated episodes of gas cooking on variability 
asthma symptoms, and medication usage in asthmatic women.

\section{Methods}

STUDY DESIGN

Observational field studies of a cross sectional design were conducted in two consecutive phases on the same group of asthmatic women who regularly cook using gas hobs. In the first phase study we investigated the effects of acute short term exposure to $\mathrm{NO}_{2}$ during single episodes of actual gas cooking on changes in PEFR. In the second phase study we investigated the effects of mean continued personal exposure to $\mathrm{NO}_{2}$ from repeated intermittent episodes of gas cooking on the PEFR variability, severity of asthma symptoms, and medication usage. All exposure and outcome measurements were made in the patient's own home.

\section{STUDY SUBJECTS}

Sixteen adult women with asthma were recruited from the asthma clinic of the National University Hospital. We estimated that a sample size of 13-29 subjects would be required for the study to detect moderate effects (correlation coefficients $0.50-0.70$ ) at two sided $5 \%$ level of significance with $80 \%$ power. All patients had persistent asthma as defined in the Global Initiative for Asthma (GINA) ${ }^{14}$ for at least 6 months. All patients had a normal chest radiograph. The diagnosis of asthma was based on (1) a convincing history of asthma characterised by recurrent episodes of wheezing and dyspnoea requiring medical intervention and showing prompt response to bronchodilators; and (2) documented evidence of variability of airflow limitation evidenced by either an increase of at least $20 \%$ in forced expiratory volume in one second $\left(\mathrm{FEV}_{1}\right)$ or PEFR in response to an inhaled short acting $\beta_{2}$ agonist or a diurnal variation in PEFR of more than $20 \%$ recorded over 14 days. ${ }^{15}$ Their severity ranged from mild to severe persistent asthma based on their most recent symptom frequencies and/or PEFR according to the GINA criteria, and all patients were receiving inhaled steroid treatment at the time of the study.

The study subjects were 20-65 years of age, cooked using gas hobs at least twice a week, had never smoked, had no family members who were smokers, had no other cardiac or chronic respiratory diseases (principally patients with fixed airflow obstruction), and were able to read and write in either English or Malay. Over a 2 week enrolment period they were provided with individual training and 2 weeks of practice baseline monitoring of their PEFR and diary recording of their asthma symptoms and medication usage to ensure that they were able to provide reliable data before they were recruited for the study.

OUTCOME MEASURES

The outcome measures of airway response were (1) PEFR, (2) respiratory symptom severity score of chest tightness, shortness of breath, wheeze and nocturnal cough, and (3) frequency of asthma attacks and rescue medication usage.

The PEFR is known to give much more variable readings and is hence less reliable than the $\mathrm{FEV}_{1}$. Although it would be preferable to measure acute changes in $\mathrm{FEV}_{1}$ from acute $\mathrm{NO}_{2}$ exposure, making the measurements at the patient's home presented more difficulties than would otherwise be the case if done under controlled conditions in the hospital (as, for example, with evaluating the effects of exposure to an occupational agent). It is also usually not feasible to make serial $\mathrm{FEV}_{1}$ measurements several times daily in order to assess serial changes in airway function. Hence, for field measurements the serial measurement of PEFR is usually preferred and it is commonly employed in community studies as an objective means of evaluating functional changes in response to environmental and occupational asthma. ${ }^{15}$

QUESTIONNAIRE

At recruitment each participant completed a modified version of the American Thoracic Society questionnaire on respiratory symptoms which has been found to be valid and applicable in previous studies of Asian populations. ${ }^{16}{ }^{17}$ Information was also collected on personal and clinical characteristics, asthma severity, and the type, frequency and duration of the use of cooking appliances.

PEFR AND ASTHMA DIARY

Enrolled patients were each given a new manufacturer calibrated mini-Wright peak flow meter with a linear scale and intensive retraining instructions on the measurement technique and serial recording of the PEFR readings. Daily PEFR variability was measured using the diurnal variation expressed as a percentage of the mean, an index that has been recommended for community studies. To ensure complete and reliable recordings the peak flow diary was designed with a maximum user friendly illustrated format in both English and Malay, with separate documentation sheets used for each day of the study. Each patient monitored their PEFR daily for 2 weeks on at least four separate occasions during each day (06.00-08.00 hours, 12.00-14.00 hours, 16.00-18.00 hours, 20.00-22.00 hours, and at other times after midnight if the patient was woken up by asthma symptoms), with triplicate readings on each occasion. PEFR readings were recorded before the use of any rescue bronchodilator medications.

\section{ASTHMA SYMPTOM SEVERITY SCORE}

The patients indicated for each day during the 2 week study period the intensity of their symptoms for each asthma symptom of cough, wheezing, chest tightness, and nocturnal attacks according to a symptom severity rating $(0=$ none, $1=$ very mild, $2=$ mild, $3=$ moderate, $4=$ severe, $5=$ very severe). For each patient a summed severity score of all asthma symptoms was obtained for each day. The symptom severity score (frequency and intensity) for 

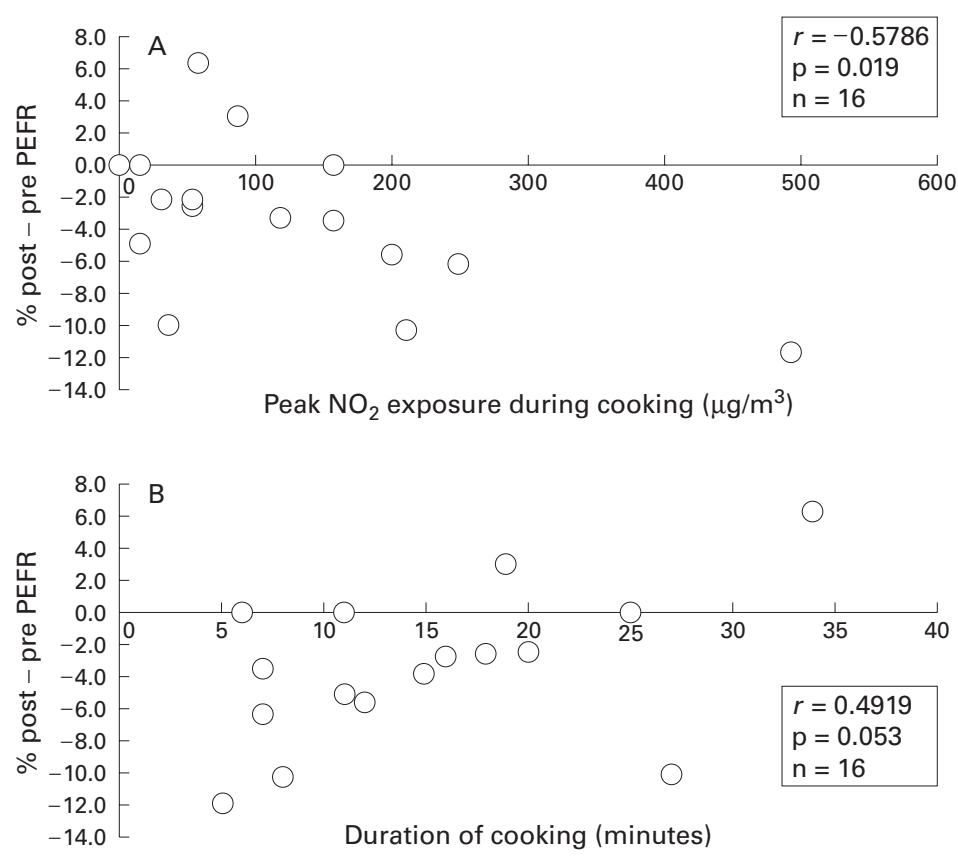

Figure 1 Peak $\mathrm{NO}_{2}$ exposure and airway response in asthmatic patients. (A) Effect of peak $\mathrm{NO}_{2}$ levels on percentage change in peak expiratory flow rate (PEFR). (B) Effect of duration of cooking on percentage change in PEFR.

each of the 2 weeks for each patient was obtained by summing the daily severity scores for the week. As the summed severity score in the first week was highly correlated with that of the second week, the summed severity score for the 2 weeks of the study period was used in subsequent analysis. The times of usage of inhaled rescue bronchodilator and stepped up corticosteroid treatment concomitant with severe asthma symptoms and "attacks" were also recorded simultaneously in separate columns in the diary.

USE OF GAS HOBS FOR COOKING

The patients recorded for each day in the dairy (1) the number of hours they spent cooking, (2) the number of times they cooked in the day, and (3) the time of the day when they cooked throughout the study period. The cooking time was taken as the duration of time when the gas stove was lit, not as the time taken to prepare for cooking.

MEAN TWO WEEK PERSONAL $\mathrm{NO}_{2}$ EXPOSURE

This was measured using passive personal $\mathrm{NO}_{2}$ sampling tubes that have been evaluated ${ }^{18}$ and used in previous studies. ${ }^{8}{ }^{20}$ The patients were each given two labelled tubes ("tube 1" and "tube 2 "), one each for weeks 1 and 2 of the study, respectively. They were instructed and reminded by telephone calls to open "tube 1 " at the beginning of the first week of the study and to close it at the end of the first week; and to open "tube 2 " at the beginning of the second week and to close it at the end of the second week of the study. The tubes were to be attached onto their outer garments and worn at all times of the day, at home and outside. They were also instructed to avoid direct damage to the tubes by fire, strong heat sources, and water, and to report any such damage to the investigator.
IMMEDIATE AIRWAY RESPONSE TO SHORT TERM $\mathrm{NO}_{2}$ EXPOSURE

The short term exposure of the patients to $\mathrm{NO}_{2}$ during a single episode of cooking was measured by active sampling during the selected cooking session, following NIOSH analytical method 6014 for $\mathrm{NO}_{2}{ }^{20}$ The sampling equipment consisted of a $\mathrm{NO}_{2}$ sampling tube containing triethanolamine coated on inert solid support, 0.25 inch outer diameter flexible tubing, and a personal sampling pump. The sampling pump was calibrated to a flow rate of $200 \mathrm{ml} / \mathrm{min}$ before use. Before the start of the selected cooking session the patients recorded three PEFR readings and a set of $\mathrm{NO}_{2}$ sampling equipment was fixed on each of the patients. The sampling tubes were fixed on the lapel of the patients and the sampling pump was carried on the belt. The sampling equipment was removed from the patients immediately after the cooking session and the sampling tube was capped and placed in an air tight container for storage and transport to the laboratory for analysis. The duration of cooking was recorded. After 10 minutes of cooking another set of three PEFR readings was recorded. Peak flow variability was measured as the percentage change in PEFR after cooking compared with before cooking:

$(100 \times$ post-PEFR - pre-PEFR $) /$ pre-PEFR

\section{LABORATORY ANALYSIS}

The samplers were analysed using the analytical procedures supplied by the manufacturer (Passam AG). The analytical method ${ }^{20}$ involves $\mathrm{NO}_{2}$ trapped on triethanolamine by a covalent bonding which undergoes a diazo coupling by adding N-1-naphthylethylene-diamine dihydrochloride (NEDA) and the absorption of the colour reagent is measured spectrophotometrically at $540 \mathrm{~nm}$.

\section{DATA ANALYSIS}

The analyses were performed using procedure from the SAS package of statistical software. Paired data analysis and correlation analyses were carried out to determine the relationships between exposure variables (cooking, $\mathrm{NO}_{2}$ exposure levels, and duration of cooking) and asthma outcome variables (PEFR variability, symptom severity score, and frequency of rescue medication usage). Data on acute short term $\mathrm{NO}_{2}$ exposure were collected for all 16 subjects and data on 2 week mean $\mathrm{NO}_{2}$ exposure were collected for 15 subjects (including one subject who happened not to cook). Analysis of the data for the mean 2 week exposure to $\mathrm{NO}_{2}$ was based on fewer than 16 subjects because of incomplete self-recording of information by three patients in their asthma diaries.

\section{Results}

STUDY PATIENTS

The 16 women ranged in age from 38 to 62 years. Six had mild persistent asthma, three had moderate persistent asthma, and seven had severe persistent asthma. All were on inhaled steroids and did not require any modification 

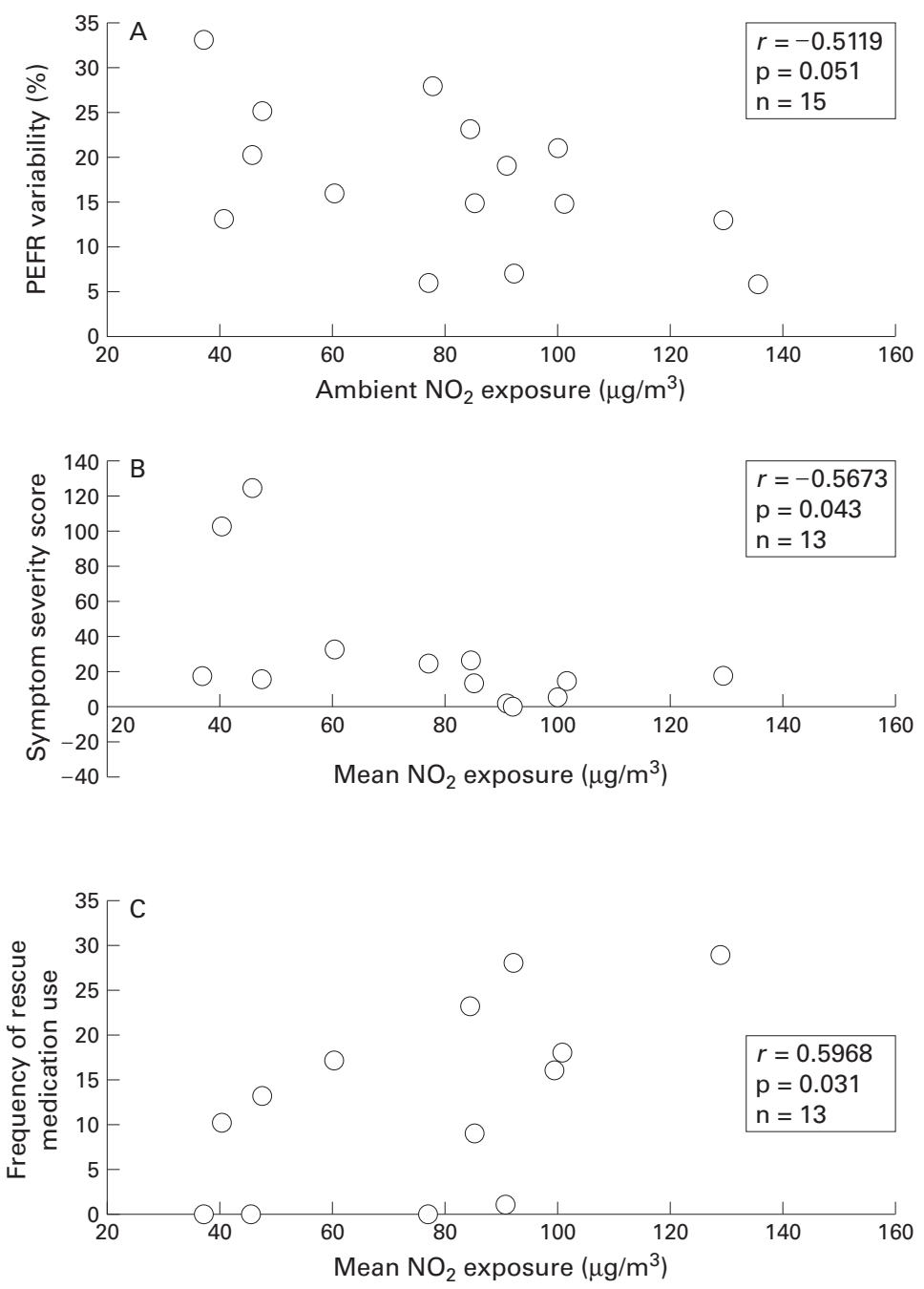

Figure 2 Mean $\mathrm{NO}_{2}$ exposure and airway response during 2 week study period. (A) Effect of ambient $\mathrm{NO}_{2}$ exposure on percentage variability in peak expiratory flow rate (PEFR). (B) Effect of mean $\mathrm{NO}_{2}$ exposure on symptom severity score. (C) Effect of mean $\mathrm{NO}_{2}$ exposure on use of rescue medication.

in their steroid usage throughout the study period.

IMMEDIATE AIRWAY RESPONSE TO SHORT TERM $\mathrm{NO}_{2}$ EXPOSURE FROM SINGLE GAS COOKING EPISODES

PEFR levels before and after cooking

PEFR levels after cooking showed a mean fall of $-3.4 \%$ (95\% CI -5.9 to -0.8$)$ from the mean (SD) pre-cooking levels of 331.9 (74.7) $1 / \mathrm{min}$, which was statistically significant $(t=2.739,15$ $\mathrm{df}, \mathrm{p}=0.015)$.

\section{Short term $\mathrm{NO}_{2}$ exposure and change in PEFR} (\%)

The short term exposure to $\mathrm{NO}_{2}$ during cooking ranged from $0.03 \mu \mathrm{g} / \mathrm{m}^{3}$ to $490.9 \mu \mathrm{g} / \mathrm{m}^{3}$ with a mean level of $121.2 \mu \mathrm{g} / \mathrm{m}^{3}$. Greater falls in PEFR from pre-cooking levels were correlated with higher levels of short term exposure to $\mathrm{NO}_{2}(r=-0.58 ; \mathrm{p}=0.019$; fig $1 \mathrm{~A})$.

Duration of cooking and change in PEFR (\%)

The duration of cooking ranged from 5 to 34 minutes with a mean duration of 15 minutes. A longer duration of cooking was associated with smaller post/pre-cooking percentage changes in PEFR ( $r=0.49$; $\mathrm{p}=0.053$; fig 1B).

Duration of cooking and acute short term $\mathrm{NO}_{2}$ exposure

However, we also observed that the level of acute short term exposure to $\mathrm{NO}_{2}$ was lower with a longer duration of cooking $(r=-0.53$; $\mathrm{p}=0.036)$.

SUBACUTE AIRWAYS RESPONSE TO MEAN TWO WEEK $\mathrm{NO}_{2}$ EXPOSURE

The mean $\mathrm{NO}_{2}$ exposure level during the 2 week study period was $80.49 \mu \mathrm{g} / \mathrm{m}^{3}$, with minimum and maximal concentrations of $37.3 \mu \mathrm{g} /$ $\mathrm{m}^{3}$ and $135.6 \mu \mathrm{g} / \mathrm{m}^{3}$. This was positively correlated with frequency of rescue bronchodilator usage $(r=0.60 ; \mathrm{p}=0.031$; fig $2 \mathrm{C}$ ) but was negatively correlated with mean PEFR variability $(r=-0.51 ; \mathrm{p}=0.051 ;$ fig $2 \mathrm{~A})$ and total symptom severity score $(r=-0.57 ; \mathrm{p}=0.043$; fig $2 \mathrm{~B})$.

Frequency of cooking and mean $\mathrm{NO}_{2}$ exposure Frequency of cooking was positively correlated with mean $\mathrm{NO}_{2}$ exposure $(r=0.5293$; $\mathrm{p}=0.042)$.

\section{Discussion}

The conflicting results of studies of the relationship between $\mathrm{NO}_{2}$ exposure and respiratory ill health may be due in part to the cross sectional nature of many study designs, as well as the selection of different study populations. In these studies secondary post hoc analyses of data of subpopulations of "high risk" subjects do not permit definitive conclusions to be drawn even if positive relationships were demonstrated. Few studies have investigated subjects with significant exposure to $\mathrm{NO}_{2}$ or vulnerable subjects with pre-existing respiratory disorders. To our knowledge there are no previous studies that have investigated the clinically deleterious effects of exposure to $\mathrm{NO}_{2}$ from actual domestic gas cooking among asthmatic patients. In the present study we have selected for investigation women who were regularly exposed to $\mathrm{NO}_{2}$ from gas cooking and who were also receiving treatment for bronchial asthma. Acute short term exposures to $\mathrm{NO}_{2}$ from single episodes of gas cooking were made in the homes of the participants, which make the results more representative of typical levels of $\mathrm{NO}_{2}$ exposure experienced during gas cooking. In Singapore the prohibition of smoking in public places and the control of vehicular emissions through strict enforcement of emission standards and restrictions on the number of vehicles on the roads limits a large proportion of exposure of these women to $\mathrm{NO}_{2}$ to the home environment. Much of the effects of recall and exposure misclassification biases usually associated with cross sectional studies with self-reported exposure data are not present in this study, although it still shares the weaknesses of observational studies in other respects.

A major methodological problem in elucidating the relationship between exposure to $\mathrm{NO}_{2}$ and respiratory health effects concerns the 
measurement of $\mathrm{NO}_{2}$ exposure. ${ }^{8}{ }^{9}$ In cross sectional studies inaccurate measurement of $\mathrm{NO}_{2}$ exposure can be due to the use of surrogate self-reported measures such as the presence of a gas stove to classify $\mathrm{NO}_{2}$ exposure. Where measured levels of $\mathrm{NO}_{2}$ were used in previous studies, the mean ambient levels of $\mathrm{NO}_{2}$ are often used but this has limitations in demonstrating precise relationships between specific modes of $\mathrm{NO}_{2}$ exposure and respiratory effects. ${ }^{138}$ This is because $\mathrm{NO}_{2}$ measurements averaged over a period of time do not characterise well the known peak concentration of $\mathrm{NO}_{2}$ that occurs during gas stove use. ${ }^{9}$

Taking a corollary from intermittent brief high intensity exposures in occupational settings, it appears reasonable to consider that peak $\mathrm{NO}_{2}$ exposures occur from single brief episodes of cooking. However, in our study the short term exposure to $\mathrm{NO}_{2}$ which occurred during single episodes of gas cooking did not, strictly speaking, measure the "peak" $\mathrm{NO}_{2}$ levels that are expected during cooking. This is a limitation in the measurement of $\mathrm{NO}_{2}$ exposure in the study. We observed that the acute short term exposure to $\mathrm{NO}_{2}$ during gas cooking varied inversely with the duration of cooking. $\mathrm{NO}_{2}$ is a product of combustion of gas fuel used for cooking. The data showed that the highest exposure to $\mathrm{NO}_{2}$ was encountered in the first 5-10 minutes of cooking and diminished exponentially thereafter. This suggests that exposure to $\mathrm{NO}_{2}$ is greatest ("peak") during the start-up of the gas appliances and in the initial 10 minutes of gas cooking when fuel combustion is still incomplete. Subsequent lower levels of peak $\mathrm{NO}_{2}$ occur when combustion becomes complete and probably also diminish over time with increased general ventilation from increased work activity and body movements.

It may also be noted that a few values of acute short term $\mathrm{NO}_{2}$ levels during cooking were indeed very low, and lower than some values of the 2 week mean exposure to $\mathrm{NO}_{2}$. Extreme (high or low) values are expected from short term exposure but not in long term mean values. The short term exposure levels during cooking vary from session to session, depending on the intensity of the gas burning rate and the direction and velocity of the air movement. Extremely low values are possible if the quantity of $\mathrm{NO}_{2}$ generated is small (from a low gas burning rate) and the air movement velocity is strong, moving $\mathrm{NO}_{2}$ away from the subject.

The duration of cooking was an inadequate surrogate measure of exposure to $\mathrm{NO}_{2}$ during cooking. At the same time it would appear that the bronchial constriction that occurs immediately after exposure to $\mathrm{NO}_{2}$ was short term and spontaneously reversible. Together, these explain why a negative relationship was found between cooking duration and PEFR variability, and is consistent with the paradoxical findings found in previous studies.

The mean $\mathrm{NO}_{2}$ levels measured over a 2 week period represent an integrated time weighted total exposure to $\mathrm{NO}_{2}$ from repeated episodes of gas cooking as well as from other ambient sources of $\mathrm{NO}_{2}$ such as vehicular traffic exhausts and passive smoking. The correlation coefficient of 0.53 suggests that gas cooking contributes about $28 \%$ of the ambient exposure to $\mathrm{NO}_{2}$ in these women. However, the actual personal continuing exposures to $\mathrm{NO}_{2}$ from gas cooking were probably greater as the frequency of gas cooking was likely to underestimate the total exposures from this source.

The possibility of other sources of measurement bias and alternative explanations should be considered as there were no procedures to "blind" the subjects or the observer in the study. We doubt that the patients' knowledge of the purpose of the investigation could have produced a fortuitous association between falls in PEFR and the measured levels of $\mathrm{NO}_{2}$ since any significant measurement bias would be likely to be present only with PEFR measurements and not $\mathrm{NO}_{2}$ measurements.

It is possible that, since Asian cooking tends to use very high temperatures and liberal amounts of spices, the noxious fumes from the cooking rather than the gas stove emissions may trigger acute irritant responses. This may well have happened to the three subjects in the study who showed quite considerable falls in PEFR (more than 10\%). This was observed in one patient with low $\mathrm{NO}_{2}$ levels, but the $\mathrm{NO}_{2}$ levels in the other two were also very high. In one subject the extreme values of $\mathrm{NO}_{2}$ level and fall in PEFR may represent statistical outliers. We re-analysed the data after excluding the extreme values of this subject, but paired comparison of the PEFR before and after gas cooking still showed a statistically significant mean difference of $8 \mathrm{l} / \mathrm{min}$ (two tailed paired $t$ test: $t=2.449,14 \mathrm{df}, \mathrm{p}=0.028)$, although the correlation coefficient was $-0.39(\mathrm{p}=0.15)$. We have no reason to believe, however, that the measurements were in any way likely to be spurious. A high correlation between emissions of $\mathrm{NO}_{2}$ and volatile organic compounds in high temperature cooking is also very likely and it may be difficult to separate their independent effects. Further investigations along these lines would be useful.

Because of the variations in the duration of cooking episodes in the present investigation, PEFR readings were recorded at varying intervals of time after 10 minutes from the commencement of each episode of cooking, rather than at a fixed time interval after peak $\mathrm{NO}_{2}$ exposure (during the first 10 minutes of cooking). The results were, indeed, fortuitous as no a priori hypotheses as such were tested, based on prior knowledge of the relationship between peak $\mathrm{NO}_{2}$ levels, duration of cooking, and onset and intensity of airway response.

The use of PEFR variability as an index of airway lability also presents some limitations in elucidating a relationship with $\mathrm{NO}_{2}$ exposure from repeated episodes of gas cooking over a period of time. For practical reasons, the number of PEFR readings was restricted to four per day. Work in the field of occupational asthma suggests that more frequent sampling is desirable in order to assess adequately PEFR variability over a short period of time. ${ }^{21}$ The timing of the PEFR measurement was also 
made at fixed intervals without due regard to its relation to the time of gas cooking by the patients. This was likely to bias the study against elucidating a relationship of increased PEFR variability with gas cooking exposure.

We observed that higher mean levels of total exposure to $\mathrm{NO}_{2}$ in these asthmatic women were associated with increased frequency of the need to use rescue bronchodilator medications. The latter represents concomitant increased frequencies of acute asthma attacks that were sufficiently severe to warrant self-medications. However, we also observed a paradoxical negative association between total exposure to $\mathrm{NO}_{2}$ and asthma exacerbations as measured by PEFR variability and the symptom severity score. There are several possible explanations for this finding. The level of $\mathrm{NO}_{2}$ encountered from daily total exposures is low, about half of the peak level that occurs during gas cooking. Within this range of exposure, airflow variability from day to day might be expected to be less. Symptom severity scoring might not have been as reliable as would be desired. Finally, the most probable reason is that increased levels of asthma exacerbations, as measured by these parameters, could have been masked by the concomitant increased use of rescue bronchodilator medications for acute attacks.

Taken together, although limitations in exposure and outcome measurements in the present study make it impossible to exclude completely some extraneous explanations for our observations, the results tend to support a link between gas cooking and respiratory effects in asthmatic women.

In conclusion, the results of the present investigation suggest that acute short term exposure to $\mathrm{NO}_{2}$ from single episodes of gas cooking is associated with immediate airflow limitation. There is some evidence to suggest that continued exposure from repeated episodes of gas cooking in asthmatic women increases asthma exacerbations.

We thank the patients and clinical staff of the National University Hospital for their help and support of this study. The study was conducted as a project in the Faculty of Medicine Undergraduate Research Opportunity Research Programme of the National University of Singapore.
1 Keller MC, Lanese RR, Mitchell R, et al. Respiratory illness in households using gas and electricity for cooking. Environ in households using gas

2 Ongston SA, Florey C, Waker CH. The Tayside infant morbidity and mortality study: effects on health of using gas for cooking. BMF 1985;290:957-60.

3 Dijkstra L, Houthuijs D, Brunekreef B, et al. Respiratory health effects of the indoor environment in a population of Dutch children. Am Rev Respir Dis 1990;142:1172-8.

4 Burr M, Anderson HR, Austin JB, et al. Respiratory symptoms and home environment in children: a national symptoms and home environm.

5 Speizer FE, Ferris BJ, Bishop YM, et al. Respiratory disease rates and pulmonary function in children associated with $\mathrm{NO}_{2}$ exposure. Am Rev Respir Dis 1980;121:3-10.

6 Dodge R. The effects of indoor pollution on Arizona children. Arch Environ Health 1982;37:151-5.

7 Ekwo EE, Weinberger MM, Lachenbruch PA, et al. Relationship of parental smoking and gas cooking to respiratory disease in children. Chest 1983;84:662-8.

8 Garrett MH, Hooper MA, Hooper BM, et al. Respiratory symptoms in children and indoor exposure to nitrogen dioxide and gas stoves. Am $\mathcal{F}$ Respir Crit Care Med 1998:158:891-5.

9 Samet JM, Utell MJ. The risk of nitrogen dioxide: what have we learned from epidemiological studies? Toxicol Ind Health 1990;6:247-62.

10 European Community Respiratory Health Survey. The associations of respiratory symptoms and lung function with the use of gas for cooking. Eur Respir F 1998;11:6518.

11 Jedrychowsky W, Tobiasz-Adamczyk, Flak E, et al. Effect of indoor air pollution caused by domestic cooking on respiratory problems of elderly women. Environ Int 1990;16:57-60

12 Ng TP, Hui KP, Tan WC. Respiratory symptoms and lung function effects of domestic exposure to tobacco smoke and cooking by gas in non-smoking women in Singapore. $\mathcal{F}$ apidemiol Community Health 1993;47:454-9.

13 Jarvis D, Chinn S, Luczynska C, et al. Association of respiratory symptoms and lung function in young adults with use of domestic gas appliances. Lancet 1996;347:426-31.

14 Global Initiative for Asthma (GINA). Global strategy for asthma management and prevention. NHLBI/WHO Workshop Report, March 1993, Publication No 95-3659. Bethesda: National Institutes of Health, National Heart, Lung \& Blood Institute, January 1995.

15 Quakenboss JJ, Lobowitz MD, Krzyanowski M. The normal range of diurnal changes in peak expiratory flow rates. Relationship to symptoms and respiratory disease. Am Rev Respir Dis 1991;143:323-30.

$16 \mathrm{Ng}$ TP, Tsin TW, O'Kelly FJ, et al. A survey of the respiratory health of silica-exposed gemstone workers in Hong tory health of silica-exposed gemstone work

17 Ng TP, Phoon WH, Lee HS, et al. An epidemiological survey of respiratory morbidity among granite quarry workers in Singapore: chronic bronchitis and lung function impairment. Ann Acad Med Singapore 1992;21:312-7.

18 Hangartner $M$. Diffusive sampling as an alternative approach for developing countries. World Congress on Air Pollution in Developing Countries, Costa Rica, 1996.

19 Koo LC, Ho JHC, Ho CY, et al. Personal exposure to nitrogen dioxide and its association with respiratory illness in Hong Kong. Am Rev Respir Dis 1990;141:1119-26.

20 NIOSH manual of analytical methods. 4th ed. Cincinnati, Ohio: US Department of Health and Human Services, Cincinnati, 1994.

21 Gannon PFG, Newton DT, Pantin CFA, et al. Effects of the number of peak flow readings a day on diurnal variation. Proceedings of the British Thoracic Society summer 1992 meeting. Thorax 1992;48:845-6. 